\title{
Concentration and chemical form of dietary zinc shape the porcine colon microbiome, its functional capacity and antibiotic resistance gene repertoire
}

\author{
Robert Pieper $\mathbb{D}^{1} \cdot$ Temesgen H. Dadi $\mathbb{D}^{1,2,3} \cdot$ Laura Pieper $\mathbb{D}^{4} \cdot$ Wilfried Vahjen $\mathbb{D}^{1} \cdot$ André Franke $\mathbb{I}^{5} \cdot$ Knut Reinert ${ }^{2}$. \\ Jürgen Zentek ${ }^{1}$
}

Received: 15 May 2020 / Revised: 2 July 2020 / Accepted: 23 July 2020 / Published online: 3 August 2020

(c) The Author(s) 2020. This article is published with open access

\begin{abstract}
Despite a well-documented effect of high dietary zinc oxide on the pig intestinal microbiota composition less is it yet known about changes in microbial functional properties or the effect of organic zinc sources. Forty weaning piglets in four groups were fed diets supplemented with 40 or $110 \mathrm{ppm}$ zinc as zinc oxide, $110 \mathrm{ppm}$ as Zn-Lysinate, or $2500 \mathrm{ppm}$ as zinc oxide. Host zinc homeostasis, intestinal zinc fractions, and ileal nutrient digestibility were determined as main nutritional and physiological factors putatively driving colon microbial ecology. Metagenomic sequencing of colon microbiota revealed only clear differences at genus level for the group receiving $2500 \mathrm{ppm}$ zinc oxide. However, a clear group differentiation according to dietary zinc concentration and source was observed at species level. Functional analysis revealed significant differences in genes related to stress response, mineral, and carbohydrate metabolism. Taxonomic and functional gene differences were accompanied with clear effects in microbial metabolite concentration. Finally, a selection of certain antibiotic resistance genes by dietary zinc was observed. This study sheds further light onto the consequences of concentration and chemical form of dietary zinc on microbial ecology measures and the resistome in the porcine colon.
\end{abstract}

\section{Introduction}

Zinc is an essential trace element, involved in manifold metabolic processes in the body [1]. In practical diets for

Supplementary information The online version of this article (https:// doi.org/10.1038/s41396-020-0730-3) contains supplementary material, which is available to authorized users.

$\triangle$ Robert Pieper

robert.pieper@fu-berlin.de

1 Institute of Animal Nutrition, Department of Veterinary Medicine, Freie Universität Berlin, Berlin, Germany

2 Department of Mathematics and Computer Science, Institute of Computer Science, Freie Universität Berlin, Berlin, Germany

3 Max Planck Institute for Molecular Genetics, Berlin, Germany

4 Institute for Veterinary Epidemiology and Biostatistics, Department of Veterinary Medicine, Freie Universität Berlin, Berlin, Germany

5 Institute of Clinical Molecular Biology, Christian-AlbrechtsUniversity of Kiel, University Hospital Schleswig Holstein, Kiel, Germany pigs, zinc must be supplemented in small amounts, (50-80 $\mathrm{ppm}$ ), in order to meet the animals requirements and prevent zinc deficiency [2,3]. Despite the need to supplement zinc to meet the zinc requirements within the legal boundaries (e.g. in the EU, the maximum permitted level for pigs is currently $150 \mathrm{mg}$ zinc/kg diet), very high dietary zinc oxide (ZnO) levels (i.e., 2000-3000 mg zinc/kg) have been shown to reduce diarrhea and improve growth performance in weaning pigs and are thus often used as effective alternative to antimicrobial growth promoters [4, 5]. Proposed mechanisms include alteration of the intestinal microbiota composition and activity, metabolic reactions in the liver, pancreas, and small intestinal tissue such as barrier function and secretory reactions [6-9]. On the other hand, the use of such high amounts of dietary zinc is regarded more and more critically due to high zinc concentrations in manure that may increase soil zinc concentrations and because of possible co-selection for antibiotic resistance among bacteria in the pig gut $[10,11]$. In the past years, organic zinc sources including certain chelates of amino acids such as glycine, lysine, or methionine have been authorized in the EU as feed additives. Although it has been often postulated that organic zinc source may have a higher bioavailability 
as compared with the inorganic sources such as $\mathrm{ZnO}$ or $\mathrm{ZnSO}_{4}$, results in the literature are sometimes not as clear [12]. Furthermore, and in contrast to studies with very high dietary $\mathrm{ZnO}$, little is yet known about the influence of inorganic and organic zinc sources at levels meeting animal requirements, on the intestinal microbiota composition and function as well as putative effects on antibiotic resistance genes in pigs.

The current study was thus conducted to compare the effect of low, normal, or very high dietary levels of dietary $\mathrm{ZnO}$ with a diet containing a normal level of an organic zinc source on zootechnical traits, body zinc status as indicator of bioavailability, and the composition and function of the intestinal microbiome in weaned piglets. It was hypothesized that the chemical form of the zinc source or low concentration of dietary $\mathrm{ZnO}$ would differentially affect the intestinal microbiome as compared with very high dietary $\mathrm{ZnO}$ due to effects on host zinc homeostasis as well as direct $\mathrm{Zn}$-dependent effects on the intestinal microbiota.

\section{Material and methods}

\section{Experimental procedures}

\section{Animals and housing}

A total of $40(\mathrm{~m} / \mathrm{f})$ Landrace piglets, weaned at the age of $25 \pm 1$ days with a mean body weight (BW) of $6.0 \pm 0.3 \mathrm{~kg}$, were placed in commercial flat deck pens ( $n=2$ piglets/pen) balancing for gender and BW. Pens were randomly assigned to one of four groups. Water and feed were provided ad libitum. The room temperature was maintained at $26^{\circ} \mathrm{C}$ on the day of weaning and reduced at regular intervals to achieve $22^{\circ} \mathrm{C}$ during the first week. Feed intake and BW of pigs were recorded weekly. Fecal consistency was scored daily based on a scale between $1=$ entirely liquid via $3=$ normal, soft and formed feces to $5=$ dry, hard pellets.

\section{Diets and diet analyses}

Four diets (Supplementary Table S1) were formulated to provide different dietary concentrations of zinc from either $\mathrm{ZnO}$ (Sigma, Taufkirchen, Germany) or zinc lysinate chelate (i.e. zinc chelate of bislysinate $\mathrm{HCl}, \mathrm{CCDC}$ deposition \#1048236, registration \#3b613 according to Reg (EG) 1831/2003). Diets were formulated to meet or exceed nutrient requirements of weaning piglets [2]. Basal dietary zinc level was supplemented with either 40 or $110 \mathrm{ppm} \mathrm{ZnO}$ (40ZnO and $110 \mathrm{ZnO}$ ) or $110 \mathrm{ppm} \mathrm{Zn}$-Lysinate (adjusted for total Lysine; 110Zn-Lys), or with $2500 \mathrm{ppm}$ with $\mathrm{ZnO}$ (2500ZnO). Titanium dioxide was added to the complete diets to allow determination of nutrient digestibility. Piglets were fed the respective diets for 3 weeks before euthanasia and subsequent sampling of gut contents. Proximate nutrients (ash, crude fiber, crude protein, ether extract), starch, and (trace) elements in the diets and digesta were determined using standard procedures. Titanium content in the diets and the digesta was measured as described [13].

\section{Sampling}

Piglets were euthanized on experimental day $21 \pm 1$ by intracardial injection of $\mathrm{T}^{\circ}{ }^{\circledR}$ (Intervet, Unterschleißheim, Germany) after sedation with ketamine hydrochloride (Ursotamin ${ }^{\circledR}$, Serumwerk Bernburg AG, Germany) and azaperone (Stresnil ${ }^{\circledR}$, Jansen-Cilag, Neuss, Germany). Pigs were euthanized $4 \mathrm{~h}( \pm 10 \mathrm{~min})$ after the morning meal to minimize bias due to different gut filling and supply of substrate for microbial fermentation. Following euthanasia, ileum and colon contents as well as tissue samples from jejunum, liver, spleen, kidney, bone (metacarpal IV), and pancreas were taken and immediately stored at $-80^{\circ} \mathrm{C}$ until further analysis.

\section{Nutrient digestibility}

Apparent ileal digestibility of dietary matter, crude protein, ether extract, starch, and zinc were calculated for all piglets ( $n=10$ /group) as follows:

Apparent ileal digestibility $(\%)=1-\left[\left(\mathrm{Ti}_{F} \times \mathrm{N}_{D}\right) /\left(\mathrm{Ti}_{D} \times \mathrm{N}_{F}\right)\right] \times 100$,

where $\mathrm{N}_{F}$ is the concentration of nutrients in the diet, $\mathrm{N}_{D}$ is the concentration of nutrients in ileal digesta, $\mathrm{Ti}_{F}$ is the concentration of titanium in the diet, and $\mathrm{Ti}_{D}$ the concentration of titanium in ileal digesta.

\section{Measures of host zinc homeostasis}

\section{Colon luminal zinc fractions}

Intestinal zinc fractions (i.e., defined here as total zinc, free zinc ions, protein-bound zinc) were determined for all piglets as described [14]. Briefly, samples were diluted (1:2 vol:vol) in water, homogenized for $1 \mathrm{~h}$ at the room temperature and centrifuged at $14,200 \times g$ for $10 \mathrm{~min}$. Supernatants were withdrawn quantitatively and applied on polymeric reversed-phase sorbent columns (8B-S100-FBJ, Phenomenex, Aschaffenburg, Germany). The resulting eluents contained the total free inorganic zinc of the samples. Protein-associated zinc was determined from eluents after elution with acetonitrile/water (4:6 vol:vol) and acetonitrile/formic acid (7:3 vol:vol) and evaporation of the organic phase by vacuum centrifugation. Total zinc in untreated digesta and the sample fractions was determined in an atomic absorption spectrometer (AAS vario 6, 
Analytik Jena, Germany) after total hydrolysis of sample fractions in hydrochloric acid (37\%) for $90 \mathrm{~min}$ at $250{ }^{\circ} \mathrm{C}$.

\section{Organ zinc concentration}

Zinc concentration in tissue samples from jejunum, liver, kidney, pancreas, bone (metacarpal IV), and spleen of all animals was determined after dry ashing at $600{ }^{\circ} \mathrm{C}$ for $8 \mathrm{~h}$ [7]. Zinc concentration was determined by atomic absorption spectrometry in an AAS vario 6 spectrometer (Analytik Jena, Jena, Germany).

\section{Expression of host zinc transporters and metallothionein}

Expression of genes related to zinc homeostasis was performed for $n=6$ piglets/group as described previously [15]. Briefly, jejunal tissue was extracted using the Nucleo Spin ${ }^{\circledR}$ kit (Macherey Nagel, Düren, Germany) and equimolar mRNA transcribed into complementary DNA. Subsequently, real-time qPCR was performed using primers targeting zinc transporter (ZnTl, ZIP4), and two metallothionein isoforms (MT-1A, MT-2B). Relative gene expression was calculated based on PCR efficiency and $\mathrm{Ct}$ values of target genes normalized using three housekeeping genes (i.e., Succinate Dehydrogenase subunit A, $\beta-2-$ microglobulin and $\beta$-actin).

\section{Microbial ecology measures}

\section{Bacterial metabolites}

Bacterial metabolites were analyzed in colon contents of $n=6$ piglets/group as described [16]. For determination of D- and L-lactate, samples were treated with $0.5 \mathrm{M}$ $\mathrm{CuSO}_{4}$ prior to analysis by high performance liquid chromatography on an Agilent 1100 chromatograph equipped with a Phenomenex C18 $(4.0 \times 2.0 \mathrm{~mm})$ guard column followed by a Phenomenex Chirex 3126 (D)penicillamine column $(150 \times 4.6 \mathrm{~mm})$ and a UV detector at $253 \mathrm{~nm}$. The carrier was $\mathrm{CuSO}_{4}$ in a gradient from 0.5 to $2.5 \mathrm{mmol} / \mathrm{l}$ with a flow rate of $1.0 \mathrm{ml} / \mathrm{min}$ at $35^{\circ} \mathrm{C}$ and the injection volume was $20 \mu \mathrm{l}$. For $\mathrm{NH}_{4}$ analysis, $20 \mu \mathrm{l}$ of a sample was chlorinated with $100 \mu \mathrm{l}$ of $0.2 \%$ alkaline hypochloride (Sigma Aldrich, Deisenhofen, Germany) to convert $\mathrm{NH}_{3}$ to chloramine $\left(\mathrm{NH}_{2} \mathrm{Cl}\right)$ following reaction with thymol to $\mathrm{N}$-chlor-2-isopropyl-5-methyl chinonmonoimin and further to indophenol using $100 \mu \mathrm{l}$ of $5 \%$ phenol nitroprusside (Sigma Aldrich, Deisenhofen, Germany). Samples were incubated in microtitration plates for $100 \mathrm{~min}$ and extinction was measured at $620 \mathrm{~nm}$ in a Tecan Sunrise ${ }^{\mathrm{TM}}$ microplate reader (Tecan Austria GmbH, Grödig, Austria). SCFA were determined by gas chromatography on an Agilent 6890 gas chromatography system with flame ionization detector and autosampler (Agilent Technologies, Böblingen, Germany). Digesta samples were acidified with oxalic acid, centrifuged for $3 \mathrm{~min}$ at $14,000 \mathrm{~g}$ followed by addition of the internal standard (caproic acid). Individual SCFA were separated on a polyethylene glycol column ( $30 \mathrm{~m}$ by $530 \mu \mathrm{m}$ by $1.00 \mu \mathrm{m}$; HP-INNOWax). Hydrogen was used as carrier gas and the injection volume was $1 \mu$. The flow rates of hydrogen and air were 20 and $400 \mathrm{ml} / \mathrm{min}$, respectively. The initial oven temperature was $70^{\circ} \mathrm{C}$, followed by an increase at a rate of $15{ }^{\circ} \mathrm{C} / \mathrm{min}$ and then a final temperature of $190^{\circ} \mathrm{C}$ for $4 \mathrm{~min}$.

\section{Metagenomic sequencing and bioinformatics}

Total genomic DNA was extracted from colon digesta of $n=6$ piglets/group using the QIAamp Fast DNA Stool Mini Kit (Qiagen, Hilden, Germany). After DNA quality control using the Genomic DNA Analysis ScreenTape on a 2200 TapeStation Instrument (Agilent Technologies) and concentration measurement using the Qubit dsDNA BR Assay Kit (Thermo Fisher Scientific), shotgun metagenomic libraries were generated using the Nextera DNA Library Preparation Kit (Illumina) according to the manufacturer's instructions. Libraries were quality-controlled using the D5000 DNA Analysis ScreenTape on a 2200 TapeStation Instrument (Agilent Technologies), and sequenced on an Illumina NextSeq500 with $2 \times 150 \mathrm{bp}$. Finally, sequencing reads were demultiplexed based on the used Nextera indices (dual indexing principle).

\section{Bacterial taxonomic analysis}

An average of $12,396,718 \pm 2,392,293$ sequences per sample was obtained ranging from $6,854,414$ to $16,794,567$. The FLEXBAR tool [17] was used to remove adapter sequences from the metagenomic reads and discard reads with length shorter than 100 nucleotides. We mapped quality checked sequences against reference genomes of 13,193 different bacterial and archaeal species taken from NCBI (ftp://ftp.ncbi.nlm.nih.gov/genomes/ genbank/). Further downstream analysis was based on the mapping results produced by yara [18]. The resulting mapping files were further analyzed using the SpeciesLevel Identification of Microorganisms from Metagenomes (SLIMM) tool [19] to produce for taxonomic profiles of each sample. We calculated relative abundances of individual taxa using the SLIMM tool. SLIMM defines relative abundance as the number of reads assigned uniquely to a species divided by the total number of mapped reads then corrected for genome sequence length. A relative abundance cut-off of $0.01 \%$ was used to consider a given taxon as present. 


\section{Functional analysis of metagenomic reads}

For functional analysis of metagenomic reads, we used the EBI Metagenomics resource (https://www.ebi.ac.uk/meta genomics/; [20]). Briefly, after quality control of initial reads and separation of rRNA coding sequences, the pipeline predicts protein coding sequences and protein family membership using the InterPro database. InterPro matches are then associated with Gene ontology (GO) terms as a method to identify relevant groups of genes that function together. GOs are summarized under three aspects: molecular function (molecular activities of gene products), cellular component (where gene products are active), and biological process (pathways and larger processes of multiple gene products) and ordered hierarchically, with less specific parent (or GO slim) terms providing an overview of the GO content, and more specific GO child terms. The relative abundances of GO slim and associated GO terms were used for further analysis.

\section{Resistome analysis}

For resistome analysis, we mapped metagenomic reads against version 1.1.2 of the Comprehensive Antibiotic Resistance Database (CARD; http://arpcard.mcmaster.ca; [21]) using yara read mapper as described above. Then we used the number of reads mapped to each resistance gene per $1000 \mathrm{bp}$ as an indicator for the relative sequence abundance for each gene. Only genes coding for a true resistance were used for further analysis, whereas genes related to multidrug resistance, transcription factors, or regulating factors were deleted from the initial list. Within AR genes coding for $\beta$-lactam resistance, ' $b l a_{C T X-M}$-type' and ' $b l a_{T E M}$-like' genes were summarized as one group, whereas the genes related to vancomycin (glycopeptide) resistance were summarized under the term 'vanB gene cluster'.

\section{Statistical analyses}

Differential abundance of bacterial genera between treatments was visualized using the hclust package in R. On the species level, we used a partial least square discriminant analysis (PLS-DA) model to determine the bacterial taxa that contributed to discrimination between experimental groups. The model values $(\mathrm{Q} 2(\mathrm{cum})>0.6$ and $\mathrm{R} 2(\mathrm{Y})>0.9)$ were used as indicators of model fit. Following, a variable importance in projection (VIP) values were obtained, where VIP is an estimation of the influence of every bacterial species on the discrimination of $y$ variables (experimental groups). Larger VIP values indicate a greater influence of a bacterial species, and VIP values of $>1$ were regarded as significant. The PLS-DA obtaining of VIP scores was performed with SIMCA-P + (Version 12.0; Umetrics, Umea, Sweden). The 60 species with the highest VIP values were then used for heatmap visualization using the hclust package in R. A Venn diagram illustrating the unique and shared bacterial species among experimental groups was drawn using the online tool 'Venny 2.1' (http://bioinfogp. cnb.csic.es/tools/venny/).

Means between treatments were analyzed by ANOVA followed Tukey post hoc test in SPSS (IBM, USA). Generally, $P<0.05$ was considered significant.

\section{Results}

\section{Animal performance, nutrient digestibility, and intestinal and body zinc status}

No clinical signs of disease were observed and diarrhea (i.e., defined as score $<2$ for 2 consecutive days) was only observed sporadically without any group effects. Feed intake and growth was low during the first experimental week. However, significantly higher feed intake was observed for $2500 \mathrm{ZnO}$ and $110 \mathrm{ZnLys}$ groups $(443 \pm 35$ and $423 \pm 16 \mathrm{~g} /$ day, respectively) as compared with $40 \mathrm{ZnO}$ and $110 \mathrm{ZnO}$ groups ( $323 \pm 18$ and $401 \pm 20 \mathrm{~g} /$ day, respectively) during the second experimental week. Concomitantly, average daily gain was higher in the $2500 \mathrm{ZnO}$ and $110 \mathrm{ZnLys}$ groups $(271 \pm 21$ and $257 \pm 19 \mathrm{~g}$ /day, respectively) as compared with $40 \mathrm{ZnO}$ and $110 \mathrm{ZnO}$ groups $(186 \pm 29$ and $238 \pm 17 \mathrm{~g} /$ day, respectively) during this period. No significant differences between groups were observed thereafter until the end of the experimental period. Similarly, feed:gain ratio was not different during the entire period (data not shown). Ileal apparent nutrient digestibility (i.e., organic matter, crude protein, ether extract, starch) did not differ between groups (Supplementary Table S2). Similarly, apparent ileal digestibility of zinc did not differ but was numerically lower in the $2500 \mathrm{ZnO}$ group. Pigs in the $2500 \mathrm{ZnO}$ group had significantly higher levels of total, free, and protein-bound zinc fractions in colon digesta as compared with the other groups (Table 1). No differences were observed between the other treatment groups. Similarly, zinc concentration in jejunal tissue, liver, kidney, and pancreas was higher $(P<0.05)$ in $2500 \mathrm{ZnO}$ group as compared with the other groups, whereas no clear differences were observed between those (Supplementary Table 3). With regard to measures of intestinal zinc homeostasis, jejunal expression of the ZIP4 gene was lower $(P<0.05)$ in $2500 \mathrm{ZnO}$ group as compared with the other dietary treatments (Supplementary Table S4). In contrast, highest expression was observed in the $2500 \mathrm{ZnO}$ group for $Z n T 1, M T 1 A$, and $M T 2 B$ genes $(P<0.05)$. No other differences were observed between the other groups, except 
Table 1 Zinc fractions (total, free, protein-bound) in colon digesta of piglets fed diets with added zinc oxide at $40 \mathrm{ppm}$ (40ZnO), $110 \mathrm{ppm}(110 \mathrm{ZnO})$, $2500 \mathrm{ppm}(2500 \mathrm{ZnO})$, or 110 ppm Zn-Lysinate (110ZnLys) over a period of 3 weeks.

\begin{tabular}{lcccrr}
\hline Item & $40 \mathrm{ZnO}$ & $110 \mathrm{ZnO}$ & $2500 \mathrm{ZnO}$ & $110 \mathrm{ZnLys}$ & $P$ value \\
\hline ppm dry matter & & & & & \\
Total zinc & $506 \pm 52^{\mathrm{a}}$ & $1013 \pm 40^{\mathrm{a}}$ & $11730 \pm 862^{\mathrm{b}}$ & $938 \pm 77^{\mathrm{a}}$ & $<0.001$ \\
Free zinc & $19 \pm 3^{\mathrm{a}}$ & $25 \pm 6^{\mathrm{a}}$ & $211 \pm 79^{\mathrm{b}}$ & $20 \pm 2^{\mathrm{a}}$ & 0.003 \\
Protein-bound zinc & $8 \pm 1^{\mathrm{a}}$ & $15 \pm 5^{\mathrm{a}}$ & $142 \pm 29^{\mathrm{b}}$ & $12 \pm 3^{\mathrm{a}}$ & $<0.001$ \\
\hline
\end{tabular}

Data are given as means $\pm \mathrm{SE}(n=10 /$ group).

Different superscripts indicate significant $(P<0.05$, Tukey post hoc test $)$ differences. for higher expression of $\mathrm{ZnTl}$ gene in $110 \mathrm{ZnO}$ as compared with $40 \mathrm{ZnO}$ group $(P<0.05)$.

\section{Colon microbiota composition, functional capacity, and antibiotic resistance genes}

Colon microbiota composition was determined based on a novel approach using metagenomic sequence alignment to known reference genomes allowing for species-level identification of bacterial taxa. Analysis of relative abundance of the dominant genera (i.e., $>0.1 \%$ relative abundance in one or more of the experimental groups) revealed only a clear and distinct clustering of colon microbiota in $2500 \mathrm{ZnO}$ group as compared with the other groups (Fig. 1). Besides a significant higher abundance of Bacteroidetes (i.e., Bacteroides, Parabacteroides) and Actinobacteria (i.e., Collinsella), most genera with higher abundance in the 2500ZnO group belonged to the Firmicutes phylum (e.g., Acetivibrio, Blautia, Coprococcus, Faecalibacterium, Subdoligranulum, Holdemania; Fig. 1, Supplementary Table S5). However, the majority of these genera did not belong to the dominant genera, but were generally of low abundance. In contrast, a significantly lower abundance of the dominating genera Megasphaera, Dialister, Acidaminococcus, and Ruminococcus was also observed in these animals (Fig. 1, Supplementary Table S5). Besides a subset $(n=3)$ of microbiomes in the $110 \mathrm{ZnO}$ group that also formed a separate cluster with a higher abundance of Bifidobacterium, Ruminococcus, and Teponema and lower abundance of Megasphaera and Prevotella, no clear patterns between the other groups were observed at phylum and genus level.

At species level, a higher diversity was generally observed in the $110 \mathrm{ZnO}$ as compared with the $2500 \mathrm{ZnO}$ group, whereas Eveness index was significantly higher in the $40 \mathrm{ZnO}$ and $110 \mathrm{ZnO}$ group as compared with the $2500 \mathrm{ZnO}$ group (Fig. 2a, b). To identify unique and shared bacterial species among groups, a Venn diagram was constructed (Fig. 2), showing that, out of a total of 274 species, 12 species were present only in the $2500 \mathrm{ZnO}$ group and another 19 species $(n=3,10$, and 6 for $110 \mathrm{ZnLys}$, $110 \mathrm{ZnO}$, and $40 \mathrm{ZnO}$, respectively) were shared between $2500 \mathrm{ZnO}$ group and one of the other groups (for details see
Supplementary Table S6), whereas no bacterial species were unique to one of the other groups. The majority of species $(239,87.2 \%)$ was shared between at least three groups. Finally, the 110ZnLys group had the lowest number of bacterial species shared with only one of the other groups. To further identify the most discriminant bacterial species between groups, PLS-DA was performed and 60 species with highest VIP scores were identified (Fig. 2d, Supplementary Table S7). The PLS-DA revealed unique and distinct patterns for all groups (Fig. 2d). Although the clearest discrimination between groups was due to different abundance or even presence/absence of individual species in $2500 \mathrm{ZnO}$ group, other discriminant species were identified in the other groups (Supplementary Table S7).

Analysis of functional capacity based on GO slim terms 'biological process' and 'molecular function' showed significant differences for a high number of terms involved i.e., in transport, DNA/RNA metabolism, translation and transcription, response to stress, binding processes, and enzyme activity (Fig. 3a, b, Supplementary Tables S8, S9). In contrast to microbiota composition (at the species level), no clear pattern could be determined for a specific dietary group. Of note, a significantly higher abundance of GO slim terms for 'carbohydrate metabolic process' (GO:0005975) as well as 'hydrolase activity' (GO:0016787) was observed in the 110ZnLys group (Fig. 3c). These two GO slim terms summarize a number of individual enzymes such as 'pectine esterase activity' (GO:0030599), ' $\alpha$-L-arabinofuranosidase activity' (GO:0046556), or ' $\alpha$-glucuronidase activity' (GO:0046559), which all showed a significantly higher abundance in both the $40 \mathrm{ZnO}$ as well as the $110 \mathrm{ZnLys}$ groups as compared with $110 \mathrm{ZnO}$ and $2500 \mathrm{ZnO}$ groups, respectively (Fig. 3d). In contrast, individual GO terms 'metal ion binding' (GO:0046872), 'metal ion transport'(GO:0030001), penicillin binding' (GO: 0008658), and ' $\beta$-lactam catabolism' (GO:0030655) had the highest abundance in $2500 \mathrm{ZnO}$ group and the lowest levels in the 110ZnLys group (Supplementary Fig. S1).

Analysis of total and individual SCFA revealed striking differences between dietary groups (Table 2$)$. Lowest $(P<$ 0.05 ) levels for total SCFA were determined in the $2500 \mathrm{ZnO}$ group followed by the $111 \mathrm{ZnO}$ group and with $40 \mathrm{ZnO}$ as well as $110 \mathrm{ZnLys}$ groups both having highest 


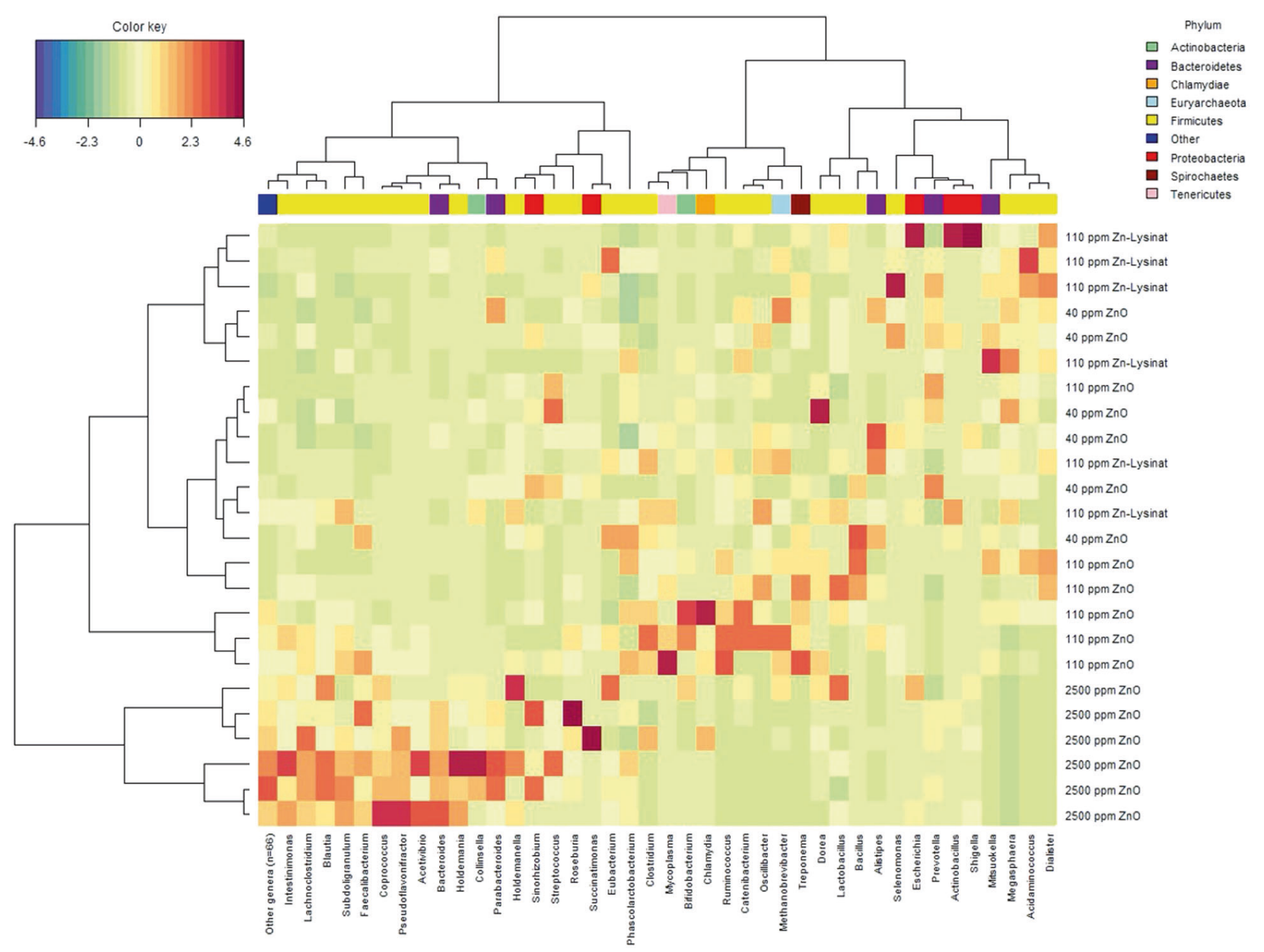

Fig. 1 High dietary zinc oxide shapes the microbial community structure in the pig colon at genus level. Heatmap showing the relative abundance of the most prevalent identified bacterial genera and related phyla in colon digesta of piglets ( $n=6 /$ group) fed diets with added zinc oxide at $40 \mathrm{ppm}(40 \mathrm{ZnO}), 110 \mathrm{ppm}(110 \mathrm{ZnO})$, $2500 \mathrm{ppm}$ (2500ZnO), or $110 \mathrm{ppm} \mathrm{Zn}$-Lysinate (110ZnLys).

group, whereas $c f x A 2$, and $\operatorname{erm}(G)$ had a higher abundance in the $40 \mathrm{ZnO}$ and $110 \mathrm{ZnLys}$ groups. well as n-butyrate levels, which had the highest total levels and molar ratio in the $40 \mathrm{ZnO}$ and $110 \mathrm{ZnLys}$ groups. Total acetate was lower in the $2500 \mathrm{ZnO}$ group but did not differ between the other groups resulting in a shift towards a higher acetate molar ratio in both the $2500 \mathrm{ZnO}$ and $110 \mathrm{ZnO}$ group as compared with the $40 \mathrm{ZnO}$ and $110 \mathrm{ZnLys}$ groups, respectively. The $\mathrm{NH}_{4}$ level was lower $(P<0.05)$ in the $2500 \mathrm{ZnO}$ group as compared with the other groups. No effects were observed for BCFA. Total and individual D- or L-lactate was only detected in small amounts in the colon and did not differ between groups.

Finally, the relative abundance of known AR genes revealed no clear differences between groups regarding the total number of AR genes and for genes conferring resistance against a certain antimicrobial class. (Fig. 4). Individual genes showed a high variability in their abundance and in relation to dietary zinc (Supplementary Table 10). However, individual genes ( $\operatorname{cph}\left(3\right.$ ")-Ib, bla $a_{R O B}, \operatorname{pat}(A), \ln u$ $(C)$, arnA) showed a higher abundance in the $2500 \mathrm{ZnO}$

\section{Discussion}

High levels of dietary $\mathrm{ZnO}$ have been and are still used as alternatives to antibiotic growth promoters in pigs [4, 5]. One major effect of very high amounts of $\mathrm{ZnO}$ in pig nutrition is the modulation of the intestinal microbial community composition, [8, 14, 22, 23]. However, less is yet known about the influence of lower concentrations of inorganic and organic zinc sources. In the present study, measurements regarding homeostatic regulation of zinc uptake, organ zinc load and excretion as well as zinc fractions in the GIT were performed to obtain a better view whether this could be associated to intestinal microbial responses. In fact, organ zinc status was clearly affected only by the high $\mathrm{ZnO}$ diet as revealed by higher zinc concentration in several organs, different expression of small intestinal zinc transporters (higher expression of 
A

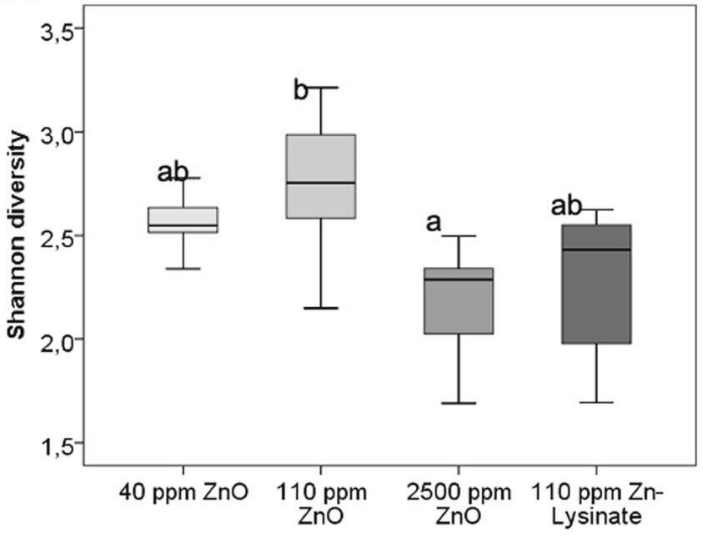

C

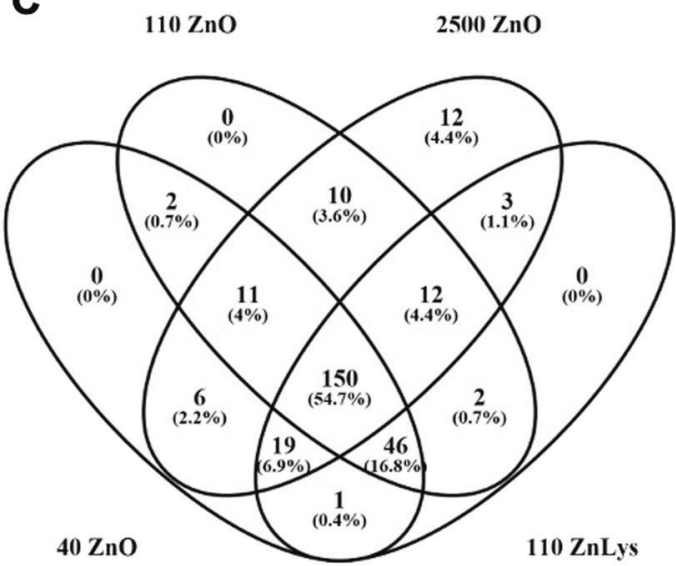

Fig. 2 Concentration and chemical form of dietary zinc shape the microbial community structure in the pig colon at species level. Microbial diversity (given as Shannon index $\mathrm{H}^{\star}$, (a) and distribution (given as Eveness, b), number of shared and unique microbial species (c), and PLS-DA scatter plot (d) of microbial communities in colon

exporter ZnT1, lower expression of zinc importer ZIP4), and a higher expression of metallothioneins MT1A and MT2B, which is a good indicator for homeostatic regulation [24, 25]. The trend towards lower apparent ileal zinc digestibility in the high $\mathrm{ZnO}$ group reflects homeostatic counter-regulation or a limitation of absorptive capacity. In contrast, there was no clear distinction for these parameters between the other dietary groups, which was also reflected by similar small intestinal luminal concentrations of total, protein-bound, and free zinc fractions. The data suggest that only minor differences existed between the $40 \mathrm{ZnO}, 110 \mathrm{ZnO}$, and $110 \mathrm{ZnLys}$, supporting previous findings $[12,26,27]$. However, the study was not designed to evaluate the bioavailability of $\mathrm{ZnO}$ versus ZnLys for both, the animal as well as intestinal microbiota. Especially the protein-bound zinc fraction could be composed of many different compounds including $\mathrm{Zn}$-amino acid chelates or more complex molecules, where $\mathrm{Zn}$ is bound to oligoor polypeptides. It is not clear whether organic zinc compounds might act differently on intestinal bacterial
B
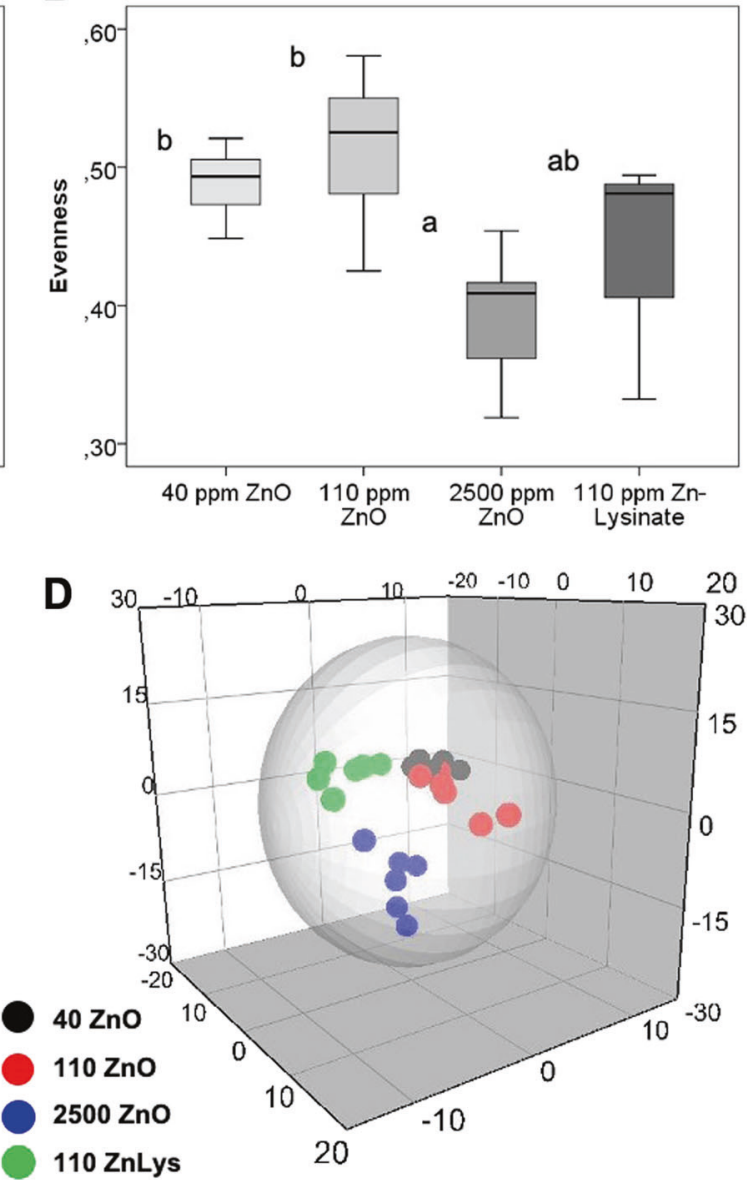

digesta of piglets fed diets with added zinc oxide at $40 \mathrm{ppm}(40 \mathrm{ZnO})$, $110 \mathrm{ppm}(110 \mathrm{ZnO}), 2500 \mathrm{ppm}(2500 \mathrm{ZnO})$, or $110 \mathrm{ppm} \mathrm{Zn}$-Lysinate $(110 \mathrm{ZnLys})$. Different superscripts indicate significant $(P<0.05)$ differences ( $n=6$ /group).

communities as compared with $\mathrm{ZnO}$ or free zinc ions. A previous study has shown the fraction of free zinc ions, but also protein-bound zinc, correlated with various and partially different parameters of intestinal microbial ecology in the colon of pigs fed high dietary $\mathrm{ZnO}$ levels [14]. The major effect is likely exerted by bacteriostatic or toxic effects of zinc ions in the gut lumen $[14,28]$. However, conclusions on genus level might be misleading towards a general susceptibility or tolerance of all members of a certain genus against zinc. For example, some members of the same genus (e.g. Bacteroides, Bifidobacterium, Clostridium) have been shown to exert a higher tolerance, whereas others were more susceptible against zinc in vitro [28]. In order to analyze the influence of zinc source and chemical form beyond genus level and omitting possible bias by analysis of 16S rRNA gene amplicons, we used a novel approach allowing to identify bacterial species by alignment of metagenomic reads to known taxa [19]. Further downstream analysis and multivariate analysis was used to identify those taxa that 


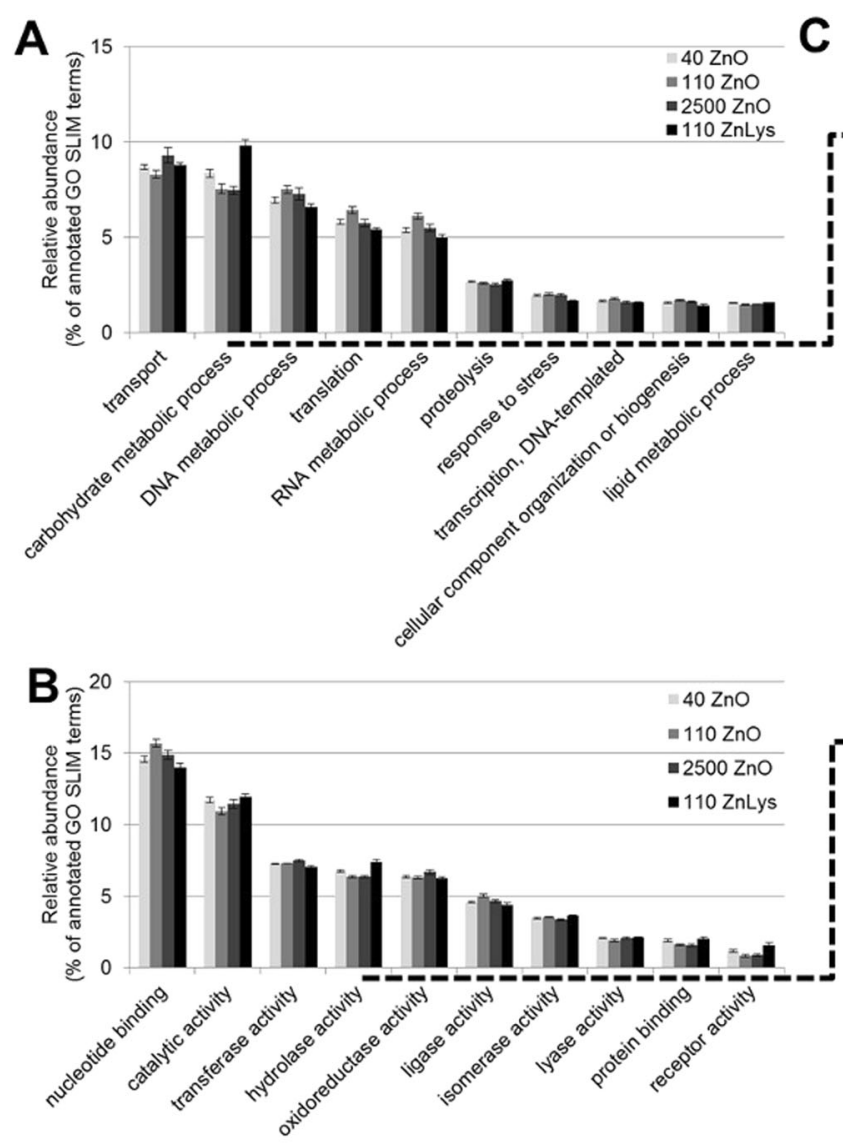

C

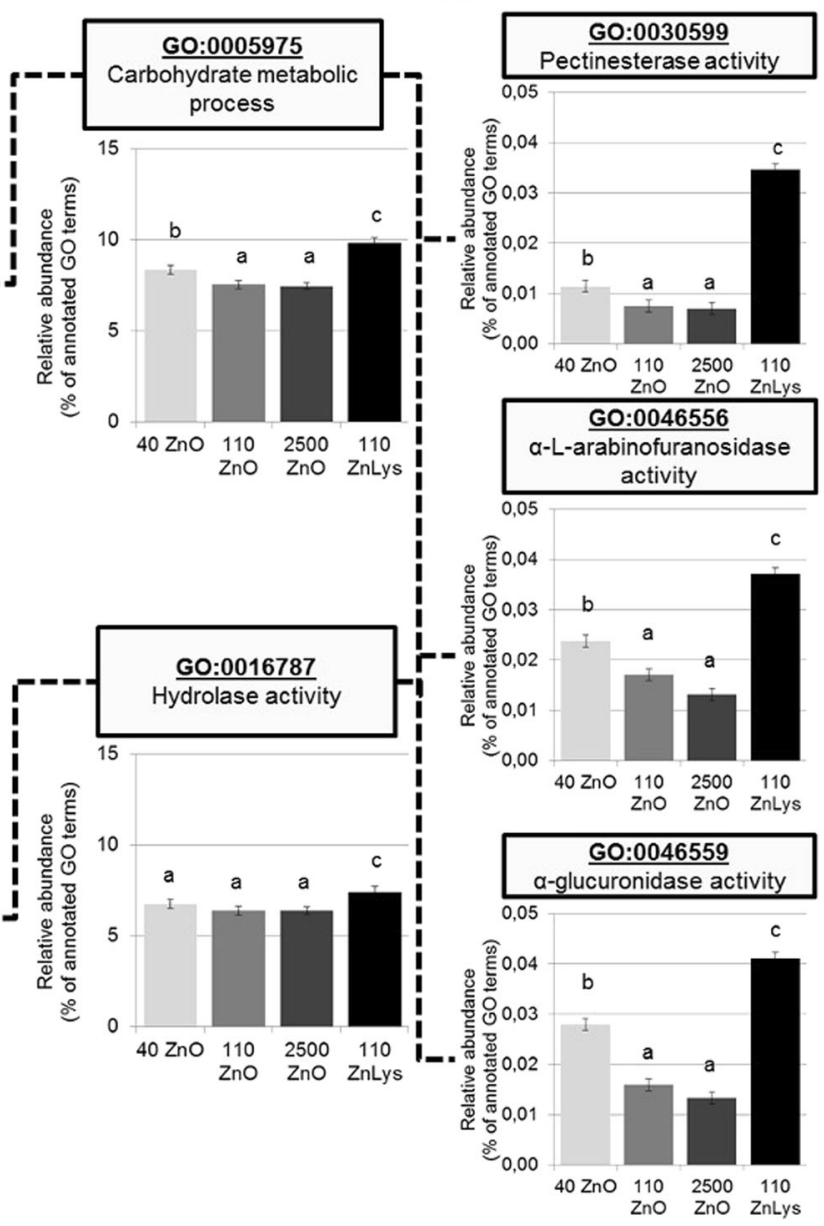

Fig. 3 Concentration and chemical form of dietary zinc shape the microbial functional capacity in the pig colon. Relative abundance of significantly affected GO slim terms related to 'biological process' (a), and 'molecular function' (b), individual GO slim terms 'carbohydrate metabolic process' and 'hydrolase activity' (c), as well as individual GO terms 'pectinesterase activity', ' $\alpha$-L-arabinofuranosidase

distinguished between the feeding groups. Of note, a previous study has postulated that high $\mathrm{ZnO}$ may increase Methanobrevibacter spp. and thereby metabolic pathways for increased methanogenesis [23]. However, in this study microbial metabolic function was predicted based on $16 \mathrm{~S}$ rRNA gene amplicons. Here, we could not find differences for the Methanobrevibacter genus. However, a trend $(P<0.1)$ for a higher abundance of the GO term 'methanogenesis' (GO:0015948, Table S8) was observed in the $2500 \mathrm{ZnO}$ group, and lowest with the $110 \mathrm{ZnLys}$ group, which could point in the same direction as previously observed [23]. It is also possible that other hydrogen sinks played a role in pigs fed the $110 \mathrm{ZnLys}$ diets, because hydrogenotrophic microorganisms generally belong to three different groups, the sulfate-reducing bacteria, methanogens and acetogens [29]. As an indicator, a typical sulfate-reducing species, Desulfovibrio piger, was found at higher abundance in the $110 \mathrm{ZnLys}$ activity', and ' $\alpha$-glucuronidase activity' (d) obtained from metagenomic sequences of microbial communities in colon digesta of piglets fed diets with added zinc oxide at $40 \mathrm{ppm}$ (40ZnO), $110 \mathrm{ppm}$ (110ZnO), $2500 \mathrm{ppm} \quad(2500 \mathrm{ZnO}), \quad$ or $110 \mathrm{ppm} \quad$ Zn-Lysinate $(110 \mathrm{ZnLys})$. Different superscripts indicate significant $(P<0.05)$ differences ( $n=6$ /group).

animals. D. piger, is likely involved in sulfate reduction through complex cross-feeding processes with Bacteroides and Actinobacterium [30]. Measurements of methanogenesis or formation of hydrogen sulfide in the context of metabolic cross-feeding could help to further evaluate this finding in the future. Species-level analysis not only revealed differences for high dietary $\mathrm{ZnO}$ levels (as already visible at genus level), but furthermore showed that the 110ZnLys group clustered separately from the other treatments. Reasons are yet not clear, because, as indicated above, no clear differences in zinc homeostasis or intestinal zinc fractions were found compared with the $110 \mathrm{ZnO}$ group. This could be due to host-driven selection of certain bacterial taxa because even small differences in dietary zinc supply have been previously shown to significantly alter systemic and gut-associated immune reactions in growing pigs $[31,32]$. It could be also speculated that certain fractions within protein-bound zinc have a specific 
Table 2 Bacterial metabolite concentrations in colon digesta of piglets fed diets with added zinc oxide at $40 \mathrm{ppm}(40 \mathrm{ZnO})$, $110 \mathrm{ppm}(110 \mathrm{ZnO}), 2500 \mathrm{ppm}$ $(2500 \mathrm{ZnO})$, or $110 \mathrm{ppm}$ Zn-Lysinate (110ZnLys) over a period of 3 weeks.

\begin{tabular}{|c|c|c|c|c|c|}
\hline Item & $40 \mathrm{ZnO}$ & $110 \mathrm{ZnO}$ & $2500 \mathrm{ZnO}$ & 110ZnLys & $P$ value \\
\hline \multicolumn{6}{|l|}{$\mathrm{mmol} / \mathrm{l}$} \\
\hline D-Lactate & $0.2 \pm 0.1$ & $0.2 \pm 0.1$ & $0.1 \pm 0.0$ & $0.1 \pm 0.0$ & 0.347 \\
\hline L-Lactate & $0.2 \pm 0.1$ & $0.2 \pm 0.1$ & $0.1 \pm 0.0$ & $0.1 \pm 0.0$ & 0.279 \\
\hline Total lactate & $0.3 \pm 0.2$ & $0.4 \pm 0.2$ & $0.1 \pm 0.0$ & $0.1 \pm 0.0$ & 0.343 \\
\hline Total SCFA & $81.5 \pm 2.7^{\mathrm{c}}$ & $68.4 \pm 4.3^{\mathrm{b}}$ & $45.9 \pm 2.8^{\mathrm{a}}$ & $80.0 \pm 3.7^{\mathrm{c}}$ & $<0.001$ \\
\hline Acetate & $41.3 \pm 1.6^{\mathrm{b}}$ & $38.3 \pm 2.6^{\mathrm{b}}$ & $27.1 \pm 1.6^{\mathrm{a}}$ & $40.6 \pm 2.4^{\mathrm{b}}$ & $<0.001$ \\
\hline Propionate & $22.7 \pm 0.9^{c}$ & $17.1 \pm 1.1^{\mathrm{b}}$ & $12.1 \pm 0.9^{\mathrm{a}}$ & $23.1 \pm 1.4^{\mathrm{c}}$ & $<0.001$ \\
\hline n-Butyrate & $11.3 \pm 0.9^{c}$ & $8.3 \pm 0.8^{b}$ & $5.0 \pm 0.3^{\mathrm{a}}$ & $10.7 \pm 0.7^{\mathrm{c}}$ & $<0.001$ \\
\hline BCFA & $2.6 \pm 0.6$ & $2.8 \pm 0.3$ & $1.2 \pm 0.2$ & $2.2 \pm 0.4$ & 0.056 \\
\hline $\mathrm{NH}_{4}$ & $10.6 \pm 1.2^{\mathrm{b}}$ & $11.4 \pm 1.0^{\mathrm{b}}$ & $4.6 \pm 0.9^{\mathrm{a}}$ & $11.6 \pm 1.3^{\mathrm{b}}$ & $<0.001$ \\
\hline Acetate $(\mathrm{Mol} \%)$ & $50.8 \pm 1.6^{\mathrm{a}}$ & $55.8 \pm 1.2^{\mathrm{b}}$ & $59.0 \pm 0.9^{\mathrm{b}}$ & $50.6 \pm 1.0^{\mathrm{a}}$ & $<0.001$ \\
\hline Propionate (Mol \%) & $27.9 \pm 0.8^{\mathrm{b}}$ & $25.0 \pm 0.6^{\mathrm{a}}$ & $26.2 \pm 0.7^{\mathrm{ab}}$ & $28.8 \pm 1.0^{\mathrm{c}}$ & 0.012 \\
\hline n-Butyrate (Mol \%) & $13.8 \pm 0.5^{\mathrm{b}}$ & $12.1 \pm 0.9^{\mathrm{ab}}$ & $10.0 \pm 0.3^{\mathrm{a}}$ & $13.3 \pm 0.3^{\mathrm{b}}$ & 0.046 \\
\hline
\end{tabular}

Data are given as means $\pm \mathrm{SE}(n=10 /$ group$)$.

Different superscripts indicate significant $(P<0.05$, Tukey post hoc test) differences.

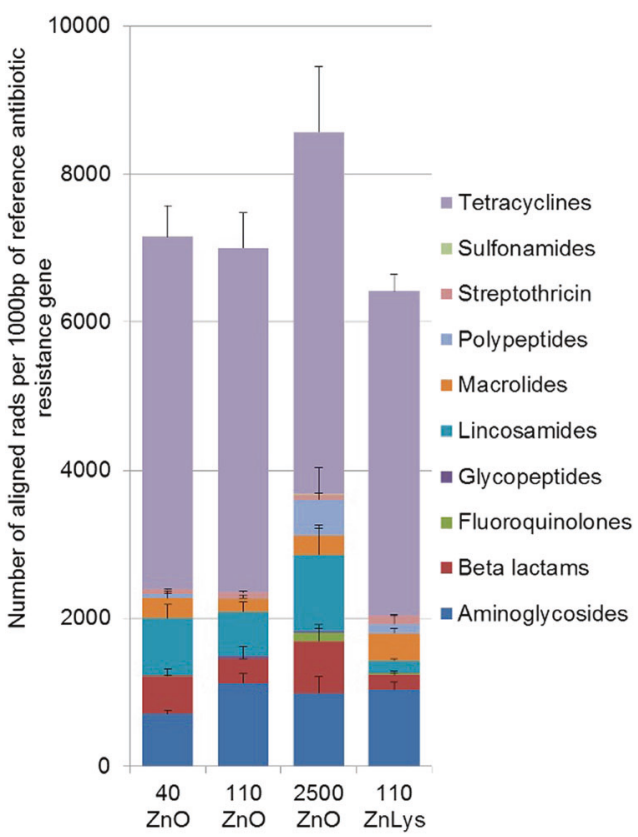

Fig. 4 Concentration and chemical form of dietary zinc alter the antibiotic resistance gene abundance in the pig colon. Relative abundance of antibiotic resistance genes (given as number of aligned reads per $1000 \mathrm{bp}$ of reference gene) identified in colon microbiomes of piglets ( $n=6 /$ group) fed diets with added zinc oxide at $40 \mathrm{ppm}$ (40ZnO), $110 \mathrm{ppm}(110 \mathrm{ZnO}), 2500 \mathrm{ppm}(2500 \mathrm{ZnO})$, or $110 \mathrm{ppm}$ $\mathrm{Zn}$-Lysinate $(110 \mathrm{ZnLys})$ over a period of 3 weeks. Individual gene abundance within each class of antibiotics is given in Supplementary Table S10.

effect on bacterial cells or, in turn, did not exert inhibitory effects as compared with diets containing 110 or $2500 \mathrm{mg}$ zinc/kg from $\mathrm{ZnO}$. During a feeding period of 3 weeks, this could contribute to a forward selection of microbial communities being more metabolically active with ZnLys as compared with $\mathrm{ZnO}$. In this context, the higher abundance of GO slim terms for 'carbohydrate metabolic process' (GO:0005975) as well as 'hydrolase activity' (GO:0016787) in the $110 \mathrm{ZnLys}$ group as well as the $40 \mathrm{ZnO}$ and their individual child-terms such as 'pectinesterase activity' (GO:0030599), ‘ $\alpha$-L-arabinofuranosidase activity' (GO: 0046556), or ' $\alpha$-glucuronidase activity' (GO:0046559) may support the latter hypothesis. They indicate a selection towards increased glycan foraging in these groups. Increased glycan foraging could be a reason for the abovementioned effects on hydrogen cross-feeding. In addition, one interesting finding was a very high abundance of Dialister succinatiphilus being able to decarboxylate succinate to propionate among pigs fed the $110 \mathrm{ZnLys}$ diets. Because shifts in intestinal microbiota communities in the present study were determined based on genomic DNA, we also measured the concentration of bacterial metabolites allowing to better distinguishing between the presence/ absence of species and their genes and their actual metabolic activity. Supporting possible cross-feeding mechanisms, the highest concentration of bacterial metabolites was found in the $40 \mathrm{ZnO}$ and the $110 \mathrm{ZnLys}$ groups. Also, the effects of high dietary $\mathrm{ZnO}$ level on bacterial metabolite concentration in the large intestine are in line with previous findings $[14,16,22]$. Interestingly, lower total SCFA and $\mathrm{NH}_{4}$ were in part also observed with the $110 \mathrm{ZnO}$ group supporting possible dose-dependent effects [16]. Whether this is due to true bacteriostatic effects of zinc ions or e.g., differences in metabolite absorption by the host is yet not clear and may warrant further studies. One previous observation was an increased concentration of lactate in the colon of pigs fed high dietary $\mathrm{ZnO}$ [22]. This was explained by the authors with differences in the availability of fermentable substrates due to feeding time and nutrient flow to the large intestine. In the present study, all pigs received the last meal $4 \mathrm{~h}$ before 
euthanasia for sampling. To exclude that the difference in bacterial metabolic activity regarding SCFA and $\mathrm{NH}_{4}$ could be due to other factors affecting the fractional nutrient flow to the large intestine, we determined the ileal nutrient digestibility but did not observe significant differences between groups. Thus, the observed differences in bacterial metabolic activity between the groups were most likely due to bacteriostatic effects of zinc ions (or other binding forms) in the gut lumen. Supporting this hypothesis, individual GO terms 'metal ion binding' (GO:0046872), 'metal ion transport'(GO:0030001), penicillin binding' (GO: 0008658), and ' $\beta$-lactam catabolism' (GO:0030655) had the highest abundance in $2500 \mathrm{ZnO}$ group and the lowest levels in the $110 \mathrm{ZnLys}$ group. This would support a forward selection of bacterial taxa with specific evolutionary adaptations through dietary zinc amount and source. It has been hypothesized already decades ago that high $\mathrm{ZnO}$ diets for weaned piglets could promote zinc tolerance and concomitant antibiotic resistance in intestinal bacteria and in manure [33-35]. For example, the use of high levels of $\mathrm{ZnO}$ in swine diets has been lately attributed with an increased prevalence of intestinal multi-resistant Escherichia coli [10, 11]. In the present study, metagenomic reads were aligned to known AR genes using the CARD database to obtain a general overview of the gut resistome in relation to zinc in the diet. The data show that, despite a generally higher abundance of cumulative AR genes in the $2500 \mathrm{ZnO}$ group, significant diets effects were only observed for a few individual genes (i.e., $\operatorname{aph}(3$ ”)-Ib, bla $\left._{R O B}, \operatorname{pat}(A), \ln u(C), \operatorname{arn} A\right)$ and not $\mathrm{AR}$ genes in general. Genes such as $a p h\left(3\right.$ ")- $I b, b l a_{R O B}$, and $\operatorname{arnA}$ can be commonly found in enterobacteria [36]. In addition, $\operatorname{aph}(3$ ")-Ib, for example, has been recently shown to be associated with higher zinc tolerance in intestinal $E$. coli from weaned piglets [37]. This is supported by our findings here and by previous studies showing an increased abundance and diversity of enterobacteria with high dietary zinc levels in pigs $[16,22,38]$. The fact that no clear difference between the other feeding groups were observed suggests that the organic zinc source and $\mathrm{ZnO}$ levels did not contribute to increased abundance of intestinal AR genes in general. Assuming that the intestinal microbiota composition stabilizes 2 weeks after the weaning in piglets, a possible forward selection of bacterial taxa by high $\mathrm{ZnO}$ as the main driver for $\mathrm{AR}$ gene abundance would not lead to significant changes in AR gene abundance beyond the 3-week period studied here. However, the present study does not allow drawing conclusions on increased resistance acquisition or possible co-selection among certain members of the microbial communities. Increased horizontal gene transfer due to high zinc concentrations (i.e. chronic exposure) might thus be associated with increased AR gene abundance beyond this time frame. However, this has yet not been shown in pigs in vivo and requires further elucidation.

\section{Conclusions}

The current study confirms the strong influence of high dietary zinc concentrations on zinc homeostasis, the large intestinal microbiome and partly also on AR genes. Further it reveals that $\mathrm{Zn}$-Lysinate as organic zinc source favors a differentially composed microbiome, enriched in genes that may promote glycan foraging and maintain a desired formation of beneficial metabolites. Consistent with previous findings, there was evidence of a weak but detectable increase in $\mathrm{AR}$ genes associated with high levels of $\mathrm{ZnO}$.

Acknowledgements We are grateful to Marita Eitinger, Katharina Topp, Anett Kriesten, Luisa Ebersbach, Corinna Schmidt, Ines Bebert, and Chris Schulze for technical support during the experiments. Open access funding provided by Projekt DEAL.

Funding The study was financially supported by ISF Schaumann Research Ltd (Wahlstedt, Germany).

\section{Compliance with ethical standards}

Conflict of interest The authors declare that they have no conflict of interest.

Ethical approval All experimental procedures were approved by the local authorities (Landesamt für Gesundheit und Soziales, Reg A 0439/17).

Publisher's note Springer Nature remains neutral with regard to jurisdictional claims in published maps and institutional affiliations.

Open Access This article is licensed under a Creative Commons Attribution 4.0 International License, which permits use, sharing, adaptation, distribution and reproduction in any medium or format, as long as you give appropriate credit to the original author(s) and the source, provide a link to the Creative Commons license, and indicate if changes were made. The images or other third party material in this article are included in the article's Creative Commons license, unless indicated otherwise in a credit line to the material. If material is not included in the article's Creative Commons license and your intended use is not permitted by statutory regulation or exceeds the permitted use, you will need to obtain permission directly from the copyright holder. To view a copy of this license, visit http://creativecommons. org/licenses/by/4.0/.

\section{References}

1. Suttle NF. Mineral nutrition of livestock. 4th ed. Wallingford (UK): CABI Publishing; 2010.

2. GfE. Empfehlungen zur Energie- und Nährstoffversorgung von Schweinen. Frankfurt: DLG Verlag; 2006.

3. NRC. Nutrient requirements of swine. 11th ed. Washington, DC: National Research Council, National Academy Press; 2012.

4. Sales J. Effects of pharmacological concentrations of dietary zinc oxide on growth of post-weaning pigs: a meta-analysis. Biol Trace Elem Res. 2013;152:343-9.

5. Heo JM, Opapeju FO, Pluske JR, Kim JC, Hampson DJ, Nyachoti $\mathrm{CM}$. Gastrointestinal health and function in weaned pigs: a review of feeding strategies to control post-weaning diarrhoea without 
using in-feed antimicrobial compounds. J Anim Physiol Anim Nutr. 2013;97:207-37.

6. Bondzio A, Pieper R, Gabler C, Weise C, Schulze P, Zentek J, et al. Feeding low or pharmacological concentrations of zinc oxide changes the hepatic proteome profiles in weaned piglets. PLoS ONE. 2013;8:e81202.

7. Pieper R, Martin L, Schunter N, Villodre Tudela C, Weise C, Klopfleisch $\mathrm{R}$, et al. Impact of high dietary zinc on zinc accumulation, enzyme activity and proteomic profiles in the pancreas of piglets. J Trace Elem Med Biol. 2015;30:3 0-36.

8. Vahjen W, Pieper R, Zentek J. Bar-coded pyrosequencing of $16 \mathrm{~S}$ rRNA gene amplicons reveals changes in ileal porcine bacterial communities due to high dietary zinc intake. Appl Environ Microbiol. 2010;76:6689-91.

9. Zakrzewski SS, Fromm M, Schulzke JD, Günzel D. Zinc strengthens the jejunal barrier by reversibly tightening the paracellular route. Am J Physiol Gastrointest Liver Physiol. 2017;313: G537-G548.

10. Bednorz C, Oelgeschläger K, Kinnemann B, Hartmann S, Neumann K, Pieper R, et al. The broader context of antibiotic resistance: zinc feed supplementation of piglets increases the proportion of multi-resistant Escherichia coli in vivo. Int J Med Microbiol. 2013;303:396-403.

11. Ciesinski L, Guenther S, Pieper R, Kalisch M, Bednorz C, Wieler LH. High dietary zinc feeding promotes persistence of multiresistant E. coli in the swine gut. PLoS ONE. 2018;13:e0191660.

12. Paulicks BR, Ingenkamp $\mathrm{H}$, Eder K. Bioavailability of two organic forms of zinc in comparison to zinc sulphate for weaning pigs fed a diet composed mainly of wheat, barley and soybean meal. Arch Anim Nutr. 2011;65:320-8.

13. Short FJ, Gorton P, Wiseman J, Boorman KN. Determination of titanium dioxide added as an inert marker in chicken digestibility studies. Anim Feed Sci Technol. 1996;59:215-21.

14. Starke IC, Pieper R, Neumann K, Zentek J, Vahjen W. The impact of high dietary zinc oxide on the development of the intestinal microbiota in weaned piglets. FEMS Microbiol Ecol. 2014;87:416-27.

15. Zetzsche A, Schunter N, Zentek J, Pieper R. Accumulation of copper in the kidney of pigs fed high dietary zinc is due to metallothionein expression with minor effects on genes involved in copper metabolism. J Trace Elem Med Biol. 2016;35:1-6.

16. Pieper R, Vahjen W, Neumann K, Van Kessel AG, Zentek J. Dose-dependent effects of dietary zinc oxide on bacterial communities and metabolic profiles in the ileum of weaned pigs. $\mathbf{J}$ Anim Physiol Anim Nutr. 2012;96:825-33.

17. Dodt M, Roehr JT, Ahmed R, Dieterich C. FLEXBAR-flexible barcode and adapter processing for next-generation sequencing platforms. Biology. 2012;1:895-905. https://doi.org/10.3390/ biology 1030895 .

18. Siragusa E, Weese D, Reinert K. Fast and accurate read mapping with approximate seeds and multiple backtracking. Nucleic Acids Res. 2013;41:e78.

19. Dadi TH, Renard BY, Wieler LH, Semmler T, Reinert K. SLIMM: species level identification of microorganisms from metagenomes. PeerJ. 2017;4:e2378v1.

20. Mitchell AL, Scheremetjew M, Denise H, Potter S, Tarkowska A, Qureshi M, et al. EBI metagenomics in 2017: enriching the analysis of microbial communities, from sequence reads to assemblies. Nucleic Acids Res. 2018;46:D726-D735.

21. Jia B, Raphenya AR, Alcock B, Waglechner N, Guo P, Tsang KK, et al. CARD 2017: expansion and model-centric curation of the comprehensive antibiotic resistance database. Nucleic Acids Res. 2017;45:D566-73.

22. Højberg O, Canibe N, Poulsen HD, Hedemann MS, Jensen BB. Influence of dietary zinc oxide and copper sulfate on the gastrointestinal ecosystem in newly weaned piglets. Appl Environ Microbiol. 2005;71:2267-77.

23. Yu T, Zhu C, Chen S, Gao L, Lv H, Feng R, et al. Dietary high zinc oxide modulates the microbiome of ileum and colon in weaned piglets. Front Microbiol. 2017;8:825.

24. Martin L, Lodemann U, Bondzio A, Gefeller EM, Vahjen W, Aschenbach JR, et al. A high amount of dietary zinc changes the expression of zinc transporters and metallothionein in jejunal epithelial cells in vitro and in vivo but does not prevent zinc accumulation in jejunal tissue of piglets. $\mathrm{J}$ Nutr. 2013;143:1205-10.

25. Brugger D, Buffler M, Windisch W. Development of an experimental model to assess the bioavailability of zinc in practical piglet diets. Arch Anim Nutr. 2014;68:73-92.

26. Schell TC, Kornegay ET. Zinc concentration in tissues and performance of weanling pigs fed pharmacological levels of zinc from $\mathrm{ZnO}, \mathrm{Zn}$-methionine, $\mathrm{Zn}$-lysine, or $\mathrm{ZnSO}_{4}$. J Anim Sci. 1996;74:1584-93.

27. Wedekind KJ, Lewis AJ, Giesemann MA, Miller PS. Bioavailability of zinc from inorganic and organic sources for pigs fed corn-soybean meal diets. J Anim Sci. 1994;72:2681-9.

28. Liedtke J, Vahjen W. In vitro antibacterial activity of zinc oxide on a broad range of reference strains of intestinal origin. Vet Microbiol. 2012;160:251-5.

29. Smith NW, Shorten PR, Altermann EH, Roy NC, McNabb WC. Hydrogen cross-feeders of the human gastrointestinal tract. Gut Microbes. 2019;10:270-88.

30. Rey FE, Gonzalez MD, Cheng J, Wu M, Ahern PP, Gordon JI. Metabolic niche of a prominent sulfate-reducing human gut bacterium. Proc Natl Acad Sci. 2013;110:13582-7.

31. Kreuzer-Redmer S, Arends D, Schulte JN, Karweina D, Korkuc P, Wöltje N, et al. High dosage of zinc modulates T-cells in a timedependent manner within porcine gut-associated lymphatic tissue. Br J Nutr. 2018;120:1349-58.

32. van Heugten E, Spears JW, Kegley EB, Ward JD, Qureshi MA. Effects of organic forms of zinc on growth performance, tissue zinc distribution, and immune response of weanling pigs. J Anim Sci. 2003;81:2063-71.

33. Jensen BB. Tarmfloraen, zinkoxid og colidiarre' hos svin (Intestinal microflora, zinc oxide and coli enteritis in pigs). Landbonyt. 1987;41:5-10.

34. Slifierz MJ, Friendship R, Weese JS. Zinc oxide therapy increases prevalence and persistence of methicillin-resistant Staphylococcus aureus in pigs: a randomized controlled trial. Zoonoses Public Health. 2015;62:301-8.

35. Yazdankhah S, Rudi K, Bernhoft A. Zinc and copper in animal feed-development of resistance and co-resistance to antimicrobial agents in bacteria of animal origin. Micro Ecol Health Dis. 2014;25:25862.

36. Ramirez MS, Tolmasky ME. Aminoglycoside modifying enzymes. Drug Resist Updat. 2010;13:151-71.

37. Johanns VC, Ghazisaeedi F, Epping L, Semmler T, Lübke-Becker A, Pfeifer Y, et al. Effects of a four-week high-dosage zinc oxide supplemented diet on commensal Escherichia coli of weaned pigs. Front Microbiol. 2019;10:2734.

38. Vahjen W, Pieper R, Zentek J. Increased dietary zinc oxide changes the bacterial core and enterobacterial composition in the ileum of piglets. J Anim Sci. 2011;89:2430-9. 